\title{
Wykorzystanie kwestionariusza LittlEARS do oceny skuteczności interwencji związanej ze stosowaniem implantu ślimakowego u małych dzieci z głębokim niedostuchem
}

\section{The LittlEARS questionnaire to assess the effectiveness of cochlear implantation in very young profoundly deaf children}

\author{
Anita Obrycka, Artur Lorens, Anna Piotrowska, Henryk Skarżyński
}

Instytut Fizjologii i Patologii Słuchu, Światowe Centrum Słuchu, Warszawa/Kajetany

Adres autora: Anita Obrycka, Światowe Centrum Słuchu, Zakład Implantów i Percepcji Słuchowej, ul. Mokra 17, Kajetany, 05-830 Nadarzyn, e-mail: a.obrycka@ifps.org.pl

Streszczenie

Wstęp: Ocena skuteczności technologii medycznej wymaga (wg schematu PICO) sprecyzowania kontekstu klinicznego $\mathrm{z}$ uwzględnieniem populacji, w której dana interwencja ma być stosowana ( $\mathrm{P}$ - ang. patient), zastosowanej interwencji ( $\mathrm{I}$ - ang. intervention), jak również opisu komparatora(ów) (C - ang. comparator) oraz efektów zdrowotnych badań klinicznych (O - ang. outcome). U małych dzieci $\mathrm{z}$ niedosłuchem, będących w okresie największej plastyczności układu słuchowego, za kluczowe uznaje się umożliwienie dokonania takiej oceny już w pierwszych miesiącach po zastosowaniu określonej technologii.

Cel: Celem pracy jest ocena skuteczności interwencji związanej ze stosowaniem implantu ślimakowego w grupie dzieci z głębokim niedosłuchem $\mathrm{w}$ wieku poniżej drugiego roku życia $\mathrm{z}$ wykorzystaniem kwestionariusza LittlEARS zgodnie ze schematem PICO.

\begin{abstract}
Materiał i metody: Grupę A, tj. badaną populację (P), stanowiło 32 dzieci, których wiek w dniu interwencji (I) - aktywacji implantu ślimakowego nie przekraczał 12 miesięcy. Komparator (C) stanowiła grupa B - 19 dzieci - użytkowników aparatów słuchowych. Dzieci z grupy B zostały wybrane w ten sposób, aby zarówno wiek w momencie badania, jak i okres korzystania $\mathrm{z}$ medycznego środka technicznego oraz głębokość niedosłuchu były porównywalne w obydwu grupach. Rodzice lub opiekunowie dzieci z badanych grup wypełniali kwestionariusz LittlEARS po około 10 miesiącach od aktywacji implantu (grupa A) lub od pierwszego dopasowania aparatów słuchowych (grupa B). Wynik badania kwestionariuszem LittlEARS wykorzystano do określenia opóźnienia rozwoju słuchowego, tj. efektów zdrowotnych zastosowanej interwencji $(\mathrm{O})$.
\end{abstract}

Wyniki: Średnie opóźnienie rozwoju słuchowego było o 14,4 miesiąca większe w grupie dzieci korzystających z aparatów słuchowych w porównaniu z grupą dzieci korzystających z implantu. Rozwój słuchowy ponad 80\% dzieci z grupy A po około 10 miesiącach korzystania z implantu ślimakowego charakteryzował się opóźnieniem nie większym niż cztery miesiące. Dla porównania - opóźnienie rozwoju słuchowego ok. 70\% dzieci z grupy B z podobnym stopniem ubytku słuchu i w podobnym wielu metrykalnym po ok. 10 miesiącach korzystania $\mathrm{z}$ aparatów słuchowych wynosiło ponad 12 miesięcy.

Wnioski: W przypadku małych dzieci z głębokim niedosłuchem implant ślimakowy stanowi skuteczną formę interwencji medycznej. Metodyka zaproponowana w niniejszej pracy umożliwia dokonanie oceny skuteczności nowych technologii medycznych u dzieci poniżej drugiego roku życia, w pierwszych miesiącach od ich zastosowania, bez konieczności prowadzenia długookresowych obserwacji.

Słowa kluczowe: dzieci • niedosłuch • implant ślimakowy • rozwój słuchowy • technologia medyczna 


\section{Abstract}

Introduction: A well-defined research question in Health Technology Assessment according to the PICO format requires structuring the clinical context considering patients (P) for whom the intervention (I) is being planned, the description of comparator(s) (C) against which intervention will be compared and outcomes $(\mathrm{O})$ to be measured. In the case of young children during the critical stage of auditory development it is crucial to assess the effectiveness of intervention already in the first months from its start.

Aim of the study: The aim of this work was to assess, according to the PICO format, the effectiveness of cochlear implantation in the group of children who were provided with this intervention before the age of two.

Material and method: The study group (i.e. patients - P) consisted of 32 children, who at the activation of cochlear implant system (I) were not older than 12 months (Group A). The comparator (C) constituted children from the group B - 19 hearing aid users, who were provided with hearing aids at the age comparable to the age at cochlear implant activation in the group A. Matching was obtained for the age at testing and the level of hearing loss in both groups. Parents of a children from both groups were asked to fill in the LittlEARS questionnaire 10 months after the first fitting of the device. The LittlEARS total score was used for the calculation of the delay in auditory development i.e. measured outcome $(\mathrm{O})$.

Results: The mean delay in auditory development in the group of hearing aid users was 14.4 months longer than in the group of cochlear implanted children. The age - appropriate auditory development or delay of this development shotter than 4 months was observed in more than $80 \%$ of cochlear implanted children. For comparison, delay in auditory development in almost $70 \%$ of children fitted with hearing aids exceeded 12 months.

Conclusions: Cochlear implantation is effective in case of very young children with profound deafness. Proposed methodology enables the assessment of effectiveness of new health technologies within the first months of their application, without the necessity of long term observations.

Key words: children $\bullet$ hearing loss $\bullet$ cochlear implant $\bullet$ auditory development $\bullet$ health technology

\begin{abstract}
Wstęp
Implanty ślimakowe to technologia medyczna, która dzięki prof. H. Skarżyńskiemu od 1992 r. jest stosowana w Polsce $\mathrm{w}$ rehabilitacji słuchowej dzieci z wrodzonym niedosłuchem odbiorczym [1]. W świetle wiedzy o konsekwencjach rozwojowych wynikających z plastyczności ośrodkowego układu nerwowego i istnieniu okresów krytycznych rozwoju funkcji sensorycznych formułowane są zalecenia wczesnej implantacji, optymalnie przed ukończeniem przez dziecko pierwszego roku życia, w celu zwiększenia skuteczności tej technologii [2,3].
\end{abstract}

Zgodnie z wytycznymi Agencji Oceny Technologii Medycznych (Health Technology Assessment, HTA) analiza skuteczności ocenianej technologii medycznej wymaga (wg schematu PICO) sprecyzowania kontekstu klinicznego $\mathrm{z}$ uwzględnieniem populacji, w której dana interwencja ma być stosowana ( $\mathrm{P}$ - ang. patient) oraz zastosowanej interwencji (I - ang. intervention), jak również opisu komparatora(ów) (C - ang. comparator) oraz efektów zdrowotnych, czyli punktów końcowych badań klinicznych (O - ang. outcome) [4,5]. W przypadku implantów ślimakowych potwierdzenie skuteczności jest konieczne, aby wczesna implantacja stała się priorytetem klinicznym.

W ramach wielu prowadzonych dotychczas badań dotyczących oceny skuteczności stosowania implantów ślimakowych u małych dzieci populację (P) stanowiły dzieci korzystające z implantu ślimakowego przez kilka lat, interwencję (I) - wszczepienie implantu ślimakowego, komparator (C) - grupa dzieci z podobnym niedosłuchem korzystających $\mathrm{z}$ aparatów słuchowych, natomiast punkty końcowe $(\mathrm{O})$ określane były na podstawie długookresowych obserwacji rozwoju kompetencji językowych dzieci [6,7]. Aby możliwe było przeprowadzenie oceny tych kompetencji w badanej populacji, konieczne było osiągnięcie przez dzieci odpowiedniego wieku. Zwykle oceny takiej dokonywano u dzieci powyżej trzeciego roku życia [8-10].

Zgodnie $\mathrm{z}$ hierarchicznym modelem rozwojowym warunkiem uczenia się mowy i języka jest wcześniejszy prawidłowy rozwój podstawowych zdolności percepcyjnych, takich jak detekcja, dyskryminacja i identyfikacja bodźców akustycznych. Po wszczepieniu implantu ślimakowego, którego celem jest kompensacja deficytu funkcji słyszenia spowodowanego znacznym lub głębokim niedosłuchem, spodziewany jest intensywny rozwój poszczególnych zdolności percepcyjnych pod warunkiem prawidłowo prowadzonego procesu rehabilitacji słuchowej. Zatem pomiar stopnia rozwoju tych zdolności mógłby być wykorzystany do określenia punktu końcowego $(\mathrm{O})$ w systemie PICO i tym samym umożliwić wczesną ocenę skuteczności stosowania implantów ślimakowych u dzieci.

U małych dzieci z niedosłuchem, będących w okresie największej plastyczności układu słuchowego, kluczowe znaczenie ma możliwość dokonania oceny skuteczności interwencji już w pierwszych miesiącach po jej zastosowaniu. Rozwiązanie takie pozwoliłoby na dokonanie weryfikacji procesu rehabilitacji słuchowej w przypadku niezadowalających efektów krótkoterminowych zastosowanej metody opieki pooperacyjnej.

W celu oceny rozwoju zdolności percepcyjnych konieczne jest stosowanie baterii testów behawioralnych 
Tabela 1. Charakterystyka badanych grup

Table 1. Characteristics of tested groups

\begin{tabular}{lcccc}
\hline & \multicolumn{2}{c}{$\begin{array}{c}\text { Dzieci korzystające z implantu } \\
\text { (grupa A) }\end{array}$} & $\begin{array}{c}\text { Dzieci korzystające z aparatów słuchowych } \\
\text { (grupa B) }\end{array}$ \\
\cline { 2 - 5 } & $\begin{array}{c}\text { Wiek w dniu badania } \\
\text { [miesiące] }\end{array}$ & $\begin{array}{c}\text { Wiek w dniu aktywacji } \\
\text { implantu [miesiące] }\end{array}$ & $\begin{array}{c}\text { Wiek w dniu badania } \\
\text { [miesiące] }\end{array}$ & $\begin{array}{c}\text { Wiek w dniu pierwszego } \\
\text { dopasowania aparatów } \\
\text { słuchowych [miesiące] }\end{array}$ \\
\hline Średnia & 20,0 & 10,5 & 20,5 & 10,2 \\
\hline SD & 1,4 & 0,9 & 1,7 & 5,7 \\
\hline min. & 18,0 & 8,4 & 18,1 & 2,8 \\
\hline max. & 23,7 & 12,0 & 22,8 & 18,4 \\
\hline
\end{tabular}

dostosowanych do wieku dziecka, jak również do stopnia rozwoju poszczególnych kompetencji słuchowych. Taka ocena wymaga prowadzenia badań kohortowych oraz złożonych analiz zgromadzonych wyników. Narażona jest ona również na wystąpienie szeregu błędów pomiarowych związanych głównie z wpływem na wyniki pomiaru czynników pozasłuchowych, takich jak: koncentracja dziecka, gotowość do współpracy, nastrój podczas badania.

Alternatywą dla oceny behawioralnej rozwoju poszczególnych zdolności percepcyjnych prowadzonej w warunkach kliniczno-laboratoryjnych jest ocena rozwoju słuchowego dziecka przez rodzica prowadzona w warunkach życia codziennego i dokumentowana za pomoca odpowiednio przygotowanych kwestionariuszy. Badania kwestionariuszowe pozwalają na usystematyzowaną ocenę rozwoju słuchowego dziecka, począwszy od odbioru bodźców akustycznych, poprzez odpowiednią reakcję na te bodźce, aż do wokalno-słownych produkcji będących odpowiedzią na stymulację słowną. Odpowiednio przygotowane kwestionariusze mogą być niezwykle pomocnym narzędziem do oceny skuteczności stosowania implantów ślimakowych. Jednakże opracowanie takiego kwestionariusza wymaga nie tylko dogłębnego przeanalizowania etapów rozwoju słuchowego małego dziecka, lecz także zastosowania wszystkich niezbędnych elementów procedury związanej $\mathrm{z}$ przygotowaniem nowego kwestionariusza, tak aby stanowił on wartościowe narzędzie diagnostyczne.

Narzędziem opracowanym w języku polskim, pozwalającym na ocenę skuteczności interwencji poprzez badanie rozwoju słuchowego $\mathrm{w}$ grupie dzieci z niedosłuchem $\mathrm{w}$ wieku poniżej drugiego roku życia, jest kwestionariusz LittlEARS [11-15]. Dla badania LittlEARS zostały wyznaczone wartości normatywne: oczekiwana i minimalna odpowiednie dla wieku badanego dziecka. Osiągnięcie przez dziecko wyniku zbliżonego do wartości oczekiwanej dla wieku oznacza osiągnięcie średniego poziomu rozwoju słuchowego dla populacji dzieci ze słuchem prawidłowym. Kwestionariusz LittlEARS jest zatem narzędziem, które może być zastosowane do bezpośredniego porównania rozwoju słuchowego $(\mathrm{O}) \mathrm{w}$ grupie dzieci $\mathrm{z}$ głębokim niedosłuchem w wieku poniżej drugiego roku życia (P), u których zastosowano implant ślimakowy (I), i dzieci w podobnym wieku, z porównywalną wadą słuchu korzystających z aparatów słuchowych (K). Dotychczas nie prowadzono badań dotyczących skuteczności zastosowania implantów ślimakowych w grupie dzieci poniżej drugiego roku życia z wykorzystaniem opisanego powyżej schematu PICO.

Celem pracy jest ocena skuteczności interwencji związanej ze stosowaniem implantu ślimakowego w grupie dzieci $\mathrm{z}$ głębokim niedosłuchem $\mathrm{w}$ wieku poniżej drugiego roku życia $\mathrm{z}$ wykorzystaniem kwestionariusza LittlEARS i zgodnie ze schematem PICO.

\section{Material i metody}

\section{Materiał}

Grupę badawczą (A) stanowiło 32 dzieci kolejno zgłaszających się do Instytutu Fizjologii i Patologii Słuchu po 1.10.2007 r. w celu aktywacji implantu ślimakowego, które spełniały następujące kryteria: wiek w dniu aktywacji implantu ślimakowego nieprzekraczający 12 miesięcy, brak zdiagnozowanych niepełnosprawności współistniejących. Komparator stanowiła grupa (B) 19 dzieci - użytkowników aparatów słuchowych. Dzieci z grupy B zostały wybrane w ten sposób, aby zarówno wiek w momencie badania, jak i okres korzystania z medycznego środka technicznego oraz głębokość niedosłuchu były porównywalne w obydwu grupach. Dane dotyczące wieku w dniu badania, wieku w dniu aktywacji medycznego środka technicznego w obydwu grupach zawiera tabela 1 .

Wszystkie dzieci z grupy A korzystały z aparatów słuchowych przed wszczepieniem implantu. Średni próg słyszenia w aparatach słuchowych przed wszczepieniem implantu był porównywalny do średniego progu słyszenia, jaki uzyskano u dzieci - użytkowników aparatów słuchowych. Oceny progu dokonano $\mathrm{z}$ wykorzystaniem audiometrii wzmocnionej bodźcem wzrokowym (ang. Visual Reinforcement Audiometry, VRA) [16]. Dane dotyczące średniego progu słyszenia w aparatach słuchowych w obydwu grupach zawiera tabela 2 .

\section{Metody}

W celu dokonania oceny skuteczności stosowania implantów ślimakowych przeprowadzono obserwacyjne badanie przekrojowe. Rodzice lub opiekunowie dzieci z badanych 
Tabela 2. Średnie wartości progów słyszenia badane w aparatach słuchowych dla użytkowników implantu ślimakowego (grupa A) i użytkowników aparatów słuchowych (grupa B); N - liczba dzieci, dla których próg dla danej częstotliwości był mierzalny

Table 2. Mean hearing thresholds measured in hearing aids in cochlear implant users (group A) and hearing aid users (group B); $\mathrm{N}$ - number of children with a measurable threshold at particular frequency

\begin{tabular}{lccccccccc}
\hline & \multicolumn{7}{c}{ Próg styszenia w aparatach słuchowych [dB] } \\
\cline { 2 - 10 } & \multicolumn{2}{c}{$\mathbf{2 5 0} \mathbf{~ \mathbf { z }}$} & \multicolumn{2}{c}{$\mathbf{5 0 0} \mathbf{~ H z}$} & \multicolumn{2}{c}{$\mathbf{1 0 0 0} \mathbf{~ H z}$} & & $\mathbf{2 0 0 0} \mathbf{~ H z}$ \\
\hline Grupa & A & B & A & B & A & B & A & B \\
\hline Średnia & 62 & 59 & 63 & 62 & 61 & 69 & 64 & 71 \\
\hline SD & 13,8 & 9,5 & 11,4 & 9,9 & 10,3 & 7,9 & 8,6 & 8,5 \\
\hline min. & 40 & 40 & 45 & 45 & 45 & 60 & 50 & 60 \\
\hline max. & 85 & 70 & 90 & 85 & 75 & 80 & 75 & 80 \\
\hline Mediana & 65 & 65 & 70 & 65 & NM & NM & NM & NM \\
\hline N & 27 & 14 & 22 & 13 & 16 & 8 & 8 & 4 \\
\hline
\end{tabular}

grup wypełniali kwestionariusz LittlEARS po około 10 miesiącach od aktywacji implantu (grupa A) lub od pierwszego dopasowania aparatów słuchowych (grupa B). Wynik badania kwestionariuszem LittlEARS wykorzystano do określenia wieku słuchowego dzieci z badanych grup zgodnie $\mathrm{z}$ metodą opracowaną przez pierwszego autora i przedstawioną na rycinie 1 [12].

Aby wykluczyć istnienie błędu systematycznego związanego z czynnikami takimi jak: wiek w dniu badania, długość okresu korzystania $\mathrm{z}$ medycznego środka technicznego oraz wartość progu słyszenia, średnie wartości tych zmiennych w obydwu grupach porównano, wykorzystując test t-Studenta i przyjmując poziom istotności $\mathrm{p}<0,05$.

\section{Wyniki}

W celu dokonania porównania opóźnienia rozwoju słuchowego w grupie dzieci korzystających z implantu ślimakowego (A) i dzieci korzystających $\mathrm{z}$ aparatów słuchowych (B) konieczne było wykluczenie czynników mogących mieć wpływ na wynik, takich jak: wiek w dniu badania, długość okresu korzystania z medycznego środka technicznego oraz głębokość niedosłuchu. Porównanie grupy dzieci korzystających z implantu ślimakowego (A) oraz grupy dzieci korzystających $\mathrm{z}$ aparatów słuchowych (B) pod względem wieku w chwili zastosowania środka technicznego (aparatu słuchowego lub implantu ślimakowego), wieku w momencie badania oraz średniego progu słyszenia $\mathrm{w}$ aparatach słuchowych nie wykazało istotnych różnic.

Wynik testu t-Studenta potwierdził hipotezę zerową o równości średnich wieku w chwili zastosowania środka technicznego $(\mathrm{t}=2,14 ; \mathrm{p}=0,83)$, średnich wieku w chwili badania $(\mathrm{t}=-1,20 ; \mathrm{p}=0,24)$ oraz średnich progów słyszenia w aparatach dla częstotliwości $250 \mathrm{~Hz}(\mathrm{t}=0,89 ; \mathrm{p}=0,38)$ i dla $500 \mathrm{~Hz}(\mathrm{t}=0,11 ; \mathrm{p}=0,91)$. Tym samym potwierdzono możliwość dokonania bezpośredniego porównania wyników badania kwestionariuszem LittlEARS w obydwu grupach.

W celu określenia opóźnienia rozwoju słuchowego dla każdego dziecka, zarówno z grupy korzystającej z implantu ślimakowego, jak i grupy korzystającej z aparatów słuchowych, wyznaczono wiek słuchowy oraz wyliczono opóźnienie rozwoju słuchowego dzieci $\mathrm{z}$ ww. grup w stosunku do dzieci ze słuchem prawidłowym, zgodnie z metodą opisaną na rycinie 1 . Średnie opóźnienie rozwoju słuchowego, wynoszące w grupie A - 1,7 miesiąca, istotnie różniło się od średniego opóźnienia (16,0 miesięcy) uzyskanego w odpowiadającej jej wiekowo grupie B. Średnie opóźnienie rozwoju słuchowego było o 14,3 miesiąca większe $\mathrm{w}$ grupie dzieci korzystających $\mathrm{z}$ aparatów słuchowych $\mathrm{w}$ porównaniu $\mathrm{z}$ grupą dzieci korzystających $\mathrm{z}$ implantu $(\mathrm{t}=10,53 ; \mathrm{p}<0,001)$ (rycina 2).

Uzyskane wartości opóźnień rozwoju słuchowego przyporządkowano do następujących przedziałów: brak opóźnienia, opóźnienie (0-4) miesiące, opóźnienie (4-8) miesięcy, opóźnienie (8-12) miesięcy, opóźnienie (12-18) miesięcy, opóźnienie powyżej 18 miesięcy. Procentowy udział dzieci z badanych grup w poszczególnych przedziałach opóźnień przedstawia rycina 3 . Rozwój słuchowy ponad $80 \%$ dzieci z grupy A po około 10 miesiącach korzystania z implantu ślimakowego charakteryzował się opóźnieniem nie większym niż czteromiesięczne. Dla porównania - opóźnienie rozwoju słuchowego ok. 70\% dzieci z grupy B z podobnym stopniem ubytku słuchu i w podobnym wieku metrykalnym po ok. 10 miesiącach korzystania z aparatów słuchowych wynosiło ponad 12 miesięcy.

\section{Dyskusja}

Oceny skuteczności interwencji związanej z zastosowaniem implantu ślimakowego dokonano, porównując opóźnienie rozwoju słuchowego wyznaczonego na podstawie wyniku LittlEARS w grupie dzieci korzystających z implantu ślimakowego i w grupie dzieci korzystających $\mathrm{z}$ aparatów słuchowych. Badane grupy zrównoważone były pod względem wieku metrykalnego, czasu korzystania z medycznego środka technicznego (implantu ślimakowego lub aparatów słuchowych) oraz głębokości niedosłuchu. Średnie opóźnienie rozwoju słuchowego w grupie dzieci korzystających $\mathrm{z}$ implantu wynosiło 1,7 miesiąca i było istotnie mniejsze w porównaniu z opóźnieniem uzyskanym w grupie dzieci 


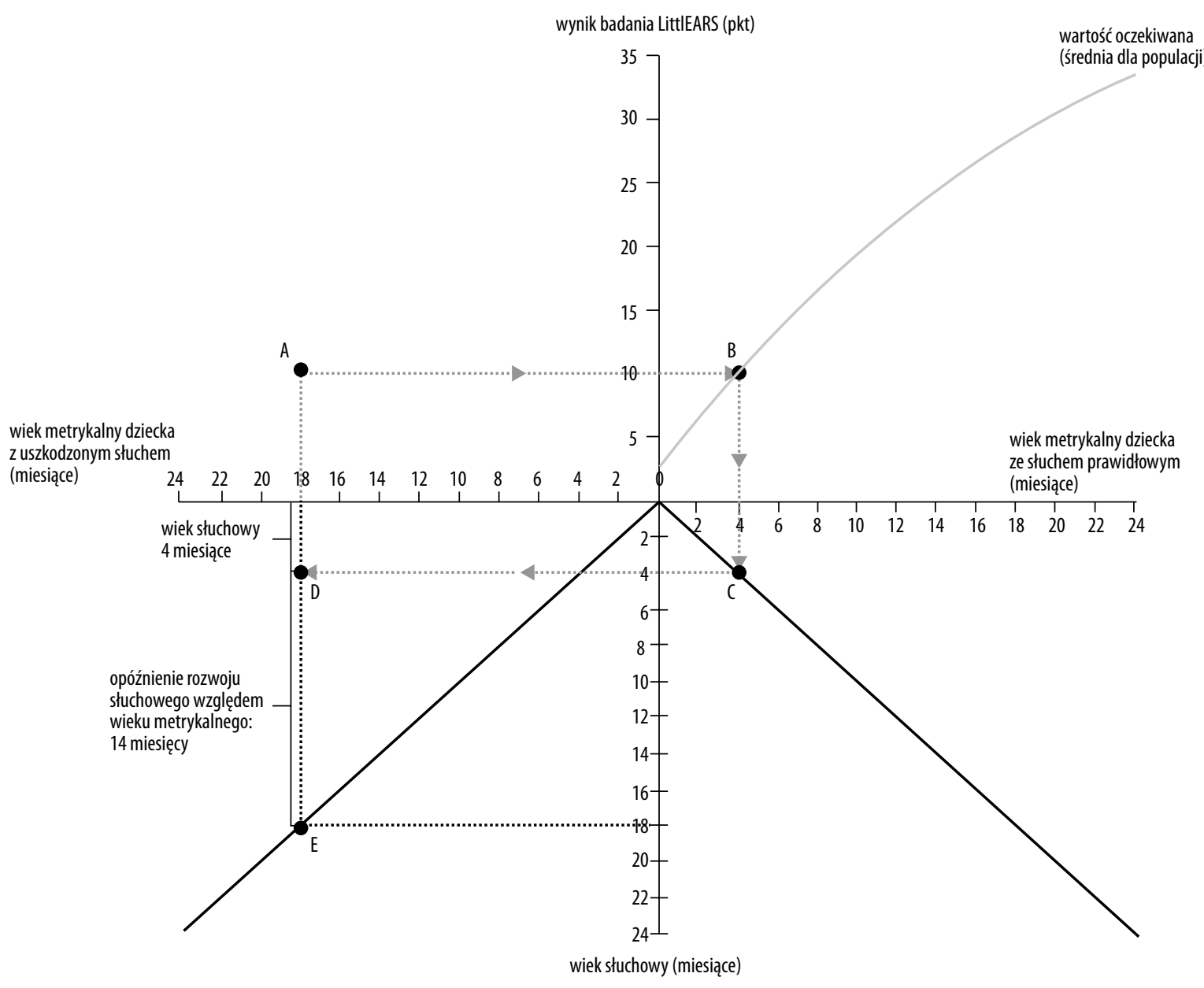

Rycina 1. Metoda wyznaczenia opóźnienia rozwoju słuchowego na przykładzie hipotetycznego wyniku badania kwestionariuszem LittIEARS. Przyjęto, że dziecko z uszkodzonym słuchem w wieku metrykalnym 18 miesięcy osiągnęło w badaniu LittlEARS wynik 10 pkt (punkt A na wykresie). Dzieci ze słuchem prawidłowym uzyskują wynik 10 pkt średnio w wieku około 4 miesiąca życia (punkt $B$ na wykresie). Dla dzieci ze słuchem prawidłowym wiek metrykalny jest tożsamy z wiekiem słuchowym (punkt C na wykresie). Dla dzieci z niedosłuchem wiek słuchowy będzie różny od wieku metrykalnego. W analizowanym przypadku wiek słuchowy dziecka z niedosłuchem wynosi 4 miesiące (punkt D na wykresie) i odpowiada wiekowi słuchowemu dziecka ze słuchem prawidłowym, które uzyskało taki sam wynik LittlEARS. Celem zastosowania medycznego środka technicznego jest dążenie do pełnej kompensacji uszkodzenia, czyli osiągnięcia stanu, w którym wiek słuchowy dziecka z uszkodzonym słuchem będzie tożsamy z wiekiem metrykalnym (punkt E na wykresie). Różnica między stanem, do którego dążymy (punkt E), i stanem faktycznym (punkt D) stanowi opóźnienie rozwoju słuchowego. Przyjęto, że opóźnienie rozwoju słuchowego wyrażone w miesiącach jest parametrem liczbowym ilościowej oceny skuteczności interwencji [12]

Figure 1. Description of methodology for the delay in auditory development calculation based on the hypothetical result of the LittIEARS questionnaire. It assumes that the age of a child with hearing loss is 18 months and the result of the LittlEARS for that child is 10 pts (point A in the graph). Mean LittlEARS total score of 10 points is expected in normal hearing children at the age of 4 months (point $B$ in the graph). For normal hearing children hearing age is equal to metrical age (point $C$ in the graph). For hearing impaired children hearing age differs from metrical age. Analyzed example shows that hearing age of hearing impaired child is 4 months (point $D$ in the graph) and corresponds to hearing age of the child with normal hearing and with the same LittlEARS total score. The aim of the application of health technology is to compensate the impairment, that is to achieve the equality of hearing age and metrical age in a child with hearing impairment (point $E$ in the graph). The difference between state of full compensation (point E) and current stage in auditory development of hearing impaired child (point D) indicates the delay in auditory development of that child. Thus the delay in auditory development can be used for the quantitative assessment of health technology effectiveness [12]

używających aparatów słuchowych wynoszącym 16 miesięcy. W grupie dzieci korzystających z implantu ślimakowego maksymalne opóźnienie nie przekraczało ośmiu miesięcy, z czego w przedziale (0-4) miesiąca zawierało się $40,6 \%$ dzieci, a prawie połowa dzieci $(43,8 \%)$ osiągnęła prawidłowy rozwój słuchowy (brak opóźnienia) (rycina 3). $\mathrm{W}$ grupie dzieci korzystających $\mathrm{z}$ aparatów słuchowych normy dla rozwoju słuchowego nie osiągnęło żadne dziecko, natomiast u prawie połowy dzieci stwierdzono opóźnienie rozwoju słuchowego powyżej osiemnastu miesięcy. 


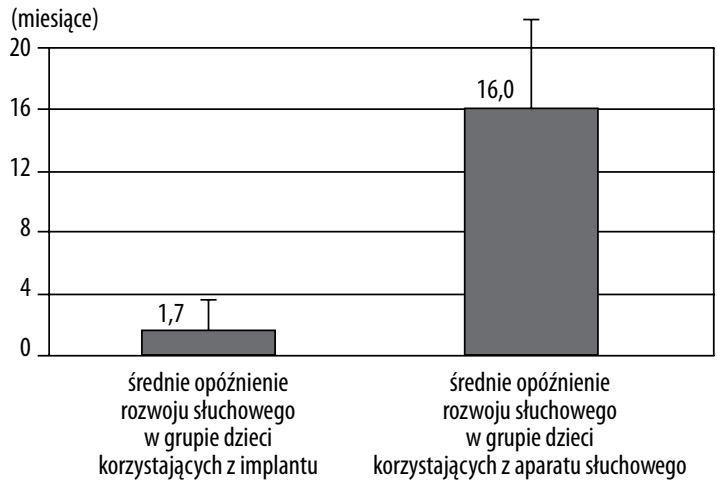

Rycina 2. Średnie opóźnienie rozwoju słuchowego w grupie dzieci korzystających z implantu ślimakowego i aparatów słuchowych (słupki wyznaczają wartość odchylenia standardowego)

Figure 2. Mean delay (with standard deviation) of auditory development in the group of cochlear implanted children and hearing aids users
Tomblin i wsp. porównali wyniki testów kompetencji językowych w grupie 29 dzieci korzystających $\mathrm{z}$ implantu i odpowiadającej jej pod względem długości korzystania z medycznego środka technicznego grupie 29 dzieci korzystających z aparatów słuchowych. Średni wiek w dniu badania wynosił 10 lat w grupie dzieci korzystających $\mathrm{z}$ implantu i 9 lat w grupie dzieci korzystających $\mathrm{z}$ aparatów słuchowych. Znaczącą różnicę na korzyść postępów rehabilitacji słuchowej w grupie dzieci z implantem zaobserwowano po dwóch latach jego używania [8]. Mildner i wsp. porównali wyniki testów dyskryminacji słów jedno- i dwusylabowych w grupie 29 dzieci korzystających z implantu ślimakowego i grupie 20 dzieci z porównywalną wadą słuchu korzystających z aparatów słuchowych [10]. Dzieci korzystające z implantu uzyskały znacząco lepsze wyniki w teście dyskryminacji mowy w porównaniu $\mathrm{z}$ dziećmi korzystającymi z aparatów. Osberger i wsp. badali natomiast 58 dzieci z głębokim niedosłuchem w wieku około 4 roku życia, które przed wszczepieniem implantu korzystały $z$ aparatów słuchowych. Wyniki testów percepcji mowy uzyskane przez te dzieci w aparatach słuchowych były znacząco gorsze w porównaniu $\mathrm{z}$ wynikami po 18 miesiącach korzystania z implantu [9]. $\square$ grupa A - dzieci korzystające z implantu $\square$ grupa B - dzieci korzystające z aparatów słuchowych

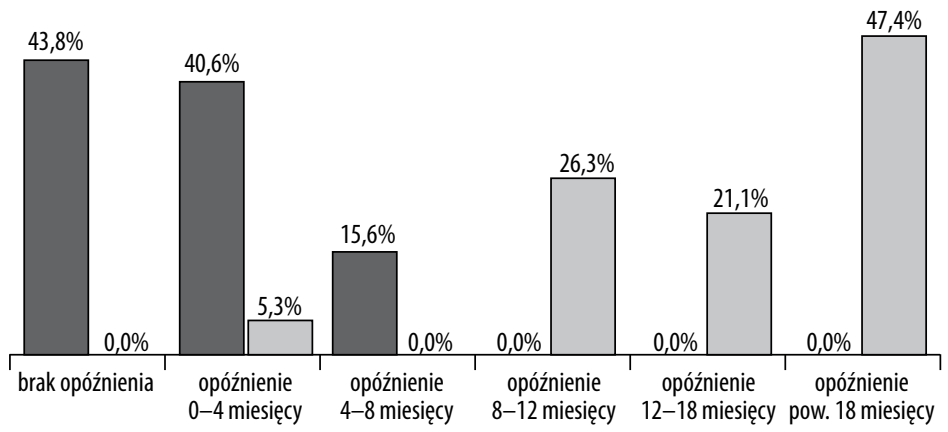

Rycina 3. Udział procentowy dzieci korzystających z implantu ślimakowego (grupa A) i dzieci korzystających z aparatów słuchowych (grupa B) w poszczególnych przedziatach opóźnienia rozwoju słuchowego

Figure 3. Percentage of cochlear implanted children (group A) and hearing aid users (group B) in different ranges of auditory development delay
Wyniki przeprowadzonego porównania świadczą o tym, że w przypadku dzieci do drugiego roku życia z głębokim niedosłuchem implant ślimakowy stanowi znacząco skuteczniejszą formę interwencji niż aparaty słuchowe. Wyniki te pozostają $\mathrm{w}$ zgodzie $\mathrm{z}$ opublikowanymi dotychczas wynikami badań długookresowych, porównujących rozwój mowy i języka w grupach dzieci z głębokim niedosłuchem korzystających $\mathrm{z}$ implantu ślimakowego i aparatów słuchowych. Porównanie wyników odległych uzyskanych przez innych autorów z wynikami uzyskanymi w pierwszych miesiącach po zastosowaniu interwencji przedstawionymi w niniejszej pracy jest możliwe dzięki założeniu o hierarchicznym charakterze rozwoju słuchowego. Obserwowany w wielu dotychczasowych badaniach rozwój mowy i języka u dzieci w wieku kilku lat możliwy był dzięki wcześniej rozwiniętym zdolnościom do detekcji, dyskryminacji i identyfikacji dźwięków.

\section{Wnioski}

W przypadku małych dzieci z głębokim niedosłuchem implant ślimakowy stanowi skuteczną formę interwencji medycznej. Metodologia zaproponowana w niniejszej pracy umożliwia dokonanie oceny skuteczności nowych technologii medycznych u dzieci poniżej drugiego roku życia już w pierwszych miesiącach po ich zastosowaniu, bez konieczności prowadzenia długookresowych obserwacji.

Projekt zostat sfinansowany ze środków Narodowego Centrum $\mathrm{Na}$ uki przyznanych na podstawie decyzji numer DEC-2012/05/N/ ST7/02006.

\section{Piśmiennictwo:}

1. Skarżyński H, Janczewski G, Niemczyk K, Geremek A. Pierwszy wszczep ślimakowy w Polsce. Otolaryngol Pol, 1993; 47(5): $444-51$.
2. Niparko J, Tobey E, Thal D, Eisenberg L, Wang N, Quittner A, Fink N. Spoken language development in children following cochlear implantation. JAMA, 2010; 303: 1498-506. 
3. Nicholas J, Geers A. Spoken language benefits of extending cochlear implant candidacy below 12 months of age. Otol Neurotol, 2013; 34: 532-8.

4. National Institute for Health and Clinical Excellence. Guide to the methods of technology appraisal. London, 2014.

5. Agencja Oceny Technologii Medycznych. Wytyczne oceny technologii medycznych (HTA). Warszawa, 2009.

6. Bond M, Mealing S, Anderson R, Elston J, Weiner G, Taylor R i wsp. The effectiveness and cost-effectiveness of cochlear implants for severe to profound deafness in children and adults: a systematic review and economic model. Health Technology Assessment, 2009; 13: 1-198.

7. National Institute for Health and Clinical Excellence. Cochlear implants for severe to profound deafness in children and adults. http://www.nice.org.uk/TA166 2011.

8. Tomblin J, Spencer L, Flock S, Tyler R, Gantz B. A comparison of language achievement in children with cochlear implants and children using hearing aids. J Speech Lang Hear Res, 1999; 42: 497-509.

9. Osberger M, Zimmerman-Phillips S, Barker M, Geier L. Clinical trial of the CLARION cochlear implant in children. Ann Otol Rhinol Laryngol Suppl, 1999; 177: 88-92.
10. Mildner V, Sindija B, Zrinski K. Speech perception of children with cochlear implants and children with traditional hearing aids. Clin Linguist Phon, 2006; 20: 219-29.

11. Obrycka A, Padilla JL, Pankowska A, Lorens A, Skarżyński H. Production and evaluation of a Polish version of the LittlEars questionnaire for the assessment of auditory development in infants. Int J Pediatr Otorhinolaryngol, 2009; 73: 1035-42.

12. Obrycka A. Adaptacja i wykorzystanie kwestionariusza LittlEARS w ocenie postępów rehabilitacji słuchowej. Rozprawa doktorska. Warszawa; 2014.

13. Tsiakpini L, Weichbold V, Kühn-Inacker H, Coninx F, D'Haese P, Almadin S. LittlEARS Auditory Questionnaire Manual. Innsbruck: MED-EL; 2004.

14. Weichbold V, Tsiakpini L, Coninx F, D’Haese P. Development of a parent questionnaire for assessment of auditory behavior of infants up to two years of age. Laryngorhinootologie, 2005; 84: $328-34$.

15. Obrycka A, Piotrowska A, Lorens A, Pankowska A, Padilla J, Skarżyński H. Adaptacja kwestionariusza LittlEARS do języka polskiego. Nowa Audiofonologia, 2013; 2: 33-9.

16. Cotton RT, Meyer CM. Practical pediatric otolaryngology. Philadelphia: Lippincott-Raven Publishers; 1999. 